\title{
The American Heart Journal
}

\begin{tabular}{lll}
\hline \hline VoL. VI & DeCEMBER, 1930 & No. 2 \\
\hline
\end{tabular}

\section{Original Communications}

\author{
THE RÔLE OF SYPHILIS IN THE ETIOLOGY OF ANGINA \\ PECTORIS, CORONARY ARTERIOSCLEROSIS AND \\ THROMBOSIS, AND OF SUDDEN CARDIAC
}

DEATH*

AldRed SCOTt WARThin, M.D., AnN Arbor, Mich.

$\mathrm{T}$ iE rôle played by syphilis in the etiology of angina pectoris, coronary sclerosis and thrombosis, and of cardiac infaretion has never been clearly evaluated; and varying opinions have been held by clinicians as to its importance in the production of these conditions. The most recent writers, as Levine, believe that syphilis is rarely an underlying factor in the causation of coronary thrombosis. In only three of Levine's eighty-nine cases in which a Wassermann reaction was done was there a positive reaction, and in one other ease with a negative reaction, there was a history of a primary'infection. From this it would appear that only 4.5 per cent of his patients were syphilitic, and it does not necessarily follow that in these eases the syphilis was the etiologie factor in the production of coronary thrombosis. In one case only, a patient only thirty-six years old, the youngest in his series, did this seem likely. In the other cases the syphilis may well have been coincidental. Levine decides that coronary thrombosis and myocardial infaretion are rarely caused by syphilis. However, in Levine's cases the diagnoses were chiefly clinical and gross pathological. In only forty-six of the eases were autopsies done, and the microseopic diagnosis of syphilis does not seem to have been considered. It is possible that microscopic eriteria for the diagnosis of syphilis might have increased the percentage of syphilities in his material. In thirteen autopsies on patients dying of coronary disease reported by W. J. Stone, microseopical examination showed syphilitic periarteritis in two cases. In eighty-six autopsies of coronary sclerosis, Willius and Brown found syphilis of the aorta in 19 per cent.

*Read before the Association of American Physicians, Atlantic City, May 6, 1930. From the Department of Pathology, University of Michigan, Ann Arbor, Mich. 
It was decided to approach the solution of this question from the standpoint of the microscopic diagnosis of syphilitic lesions, as this has never been carried out before on any large series of cases. In the twenty years, 1909 to 1929, there were in the Pathological Laboratory of the University of Michigan, 1675 autopsies on individuals over twenty-five years of age. Of this number, there were 408 males and 86 females that showed the microscopic lesions of active latent syphilis. These lesions consisted of characteristic perivascular infiltrations of lymphocytes and plasma cells around small vessels, with obliteration of the arterioles and resultant fibrosis. In about 50 per cent of cases the presence of spirocheta pallida was demonstrated in this lesion. The highest incidence of these lesions was found in the aorta; 97.6 per cent of cases for the first decade, 1909 to 1919 ; in 86.3 per cent of cases for the second decade, 1919 to 1929.

TABLE I*

\begin{tabular}{|c|c|c|c|}
\hline YEAR & $\begin{array}{l}\text { TOTAL AUTOPSIES } \\
\text { OVER } 25 \text { YEARS }\end{array}$ & $\begin{array}{c}\text { MALES WITH } \\
\text { LATENT SYPHILTS }\end{array}$ & $\begin{array}{l}\text { FEMALES WITH } \\
\text { LATENT SYPHILIS }\end{array}$ \\
\hline 1910 & 11 & 1 & 0 \\
\hline 1911 & 20 & 3 & 1 \\
\hline 1912 & 26 & 5 & 1 \\
\hline 1913 & 24 & 8 & 3 \\
\hline 1914 & 31 & 10 & 0 \\
\hline 1915 & 35 & 17 & 4 \\
\hline 1916 & 48 & 19 & 3 \\
\hline 1917 & 90 & 36 & 9 \\
\hline 1918 & 40 & 16 & 3 \\
\hline 1919 & 61 & 20 & 3 \\
\hline 1920 & 94 & 26 & 4 \\
\hline 1921 & 84 & 22 & 7 \\
\hline 1922 & 95 & 18 & 5 \\
\hline 1923 & 116 & 23 & 8 \\
\hline 1924 & 133 & 25 & 6 \\
\hline 1925 & 137 & 33 & 6 \\
\hline 1926 & 199 & 48 & 8 \\
\hline 1927 & 203 & 33 & 5 \\
\hline 1928 & 177 & 32 & 8 \\
\hline \multirow[t]{2}{*}{1929} & 51 & 13 & 2 \\
\hline & $\overline{1675}$ & 408 & $\overline{86}$ \\
\hline
\end{tabular}

*Cases of latent syphilis occurring in autopsies on adults over twenty-five years of age, in the Pathological Laboratory of the University of Michigan, during the last twenty years.

The distribution of these microscopic lesions of latent syphilis in the various organs and tissues is shown for the first decade in Table II, and for the second decade in Table III. These percentages show the preponderance of the aortic lesions over all others, followed by the meninges, testis and heart.

The microscopical study of the heart and coronary vessels shows the following: In 169 cases of syphilis (1909 to 1919) there were fiftythree cases of coronary sclerosis without thrombosis, nine cases of syphilitic disease of the coronaries, one case of coronary thrombosis 
and sclerosis, and no case with a clinical history of angina pectoris. In this decade there were thirteen cases of sudden death without previous anginal history, in the 169 cases of syphilis. Nine of these cases showed marked coronary sclerosis without evidence of syphilitic coronary involvement; four cases showed the lesions of coronary selerosis and syphilis. In nine of these cases there was a diffuse interstitial myocarditis of the syphilitic type; in four only was there a microscopic picture of myocardial infaretion.

TABLE II*

\begin{tabular}{lcccc}
\hline \multicolumn{1}{c}{ TISSUE } & $\begin{array}{c}\text { TOTAL } \\
\text { EXAMINED }\end{array}$ & $\begin{array}{c}\text { No. } \\
\text { SYPHILITIC }\end{array}$ & $\begin{array}{c}\text { PER CENT } \\
\text { SYPHILITIC }\end{array}$ & $\begin{array}{c}\text { No. } \\
\text { SUSPICIOUs }\end{array}$ \\
\hline Spinal cord & 8 & 4 & 50.0 & \\
Brain & 36 & 19 & 52.78 & \\
Meninges & 40 & 39 & 97.5 & \\
Aorta & 163 & 159 (6 aneurysms) & 97.6 & 4 \\
Heart & 169 & $113(3$ aneurysms $)$ & 66.9 & 5 \\
Liver & 165 & 46 (4 gummas) & 27.8 & 13 \\
Adrenals & 153 & 47 & 30.7 & 1 \\
Pancreas & 163 & 72 & 44.1 & 4 \\
Testis & 137 & 118 & 86.1 & 5 \\
\hline
\end{tabular}

*Distribution of Lesions of Latent Syphilis in 169 Cases of Syphills $(142$ males, 27 females), in 368 autopsies over 25 years of age, 1909-1919. 43.7 per cent latent syphilitícs.

TABLE III*

\begin{tabular}{lcccc}
\hline \multicolumn{1}{c}{ TISSUE } & $\begin{array}{c}\text { TOTAL } \\
\text { EXAMINED }\end{array}$ & $\begin{array}{c}\text { NO. } \\
\text { SYPHILITI }\end{array}$ & $\begin{array}{c}\text { PER CENT } \\
\text { SYPHILITIC }\end{array}$ & $\begin{array}{c}\text { No. } \\
\text { SUSPICIOUS }\end{array}$ \\
\hline Spinal cord & 60 & 27 & 45.0 & 1 \\
Brain & 198 & 71 (4 gummas $)$ & 39.9 & 2 \\
Meninges & 202 & 168 (2 gummas) & 83.2 & 0 \\
Aorta & 327 & 282 (29 aneurysms) & 86.3 & 7 \\
Heart & 330 & 216 (2 gummas $)$ & 65.5 & 7 \\
Iiver & 328 & 102 (12 gummas) & 31.4 & 4 \\
Adrenals & 320 & 145 (1 gumma) & 45.3 & 2 \\
Pancreas & 328 & 98 ( 2 gummas) & 29.8 & 0 \\
Testis & 264 & 203 & 76.5 & 10 \\
\hline
\end{tabular}

*Distribution of Lesions of Latent Syphilis in 332 Cases of Syphilis (275 males, 57 females) in 1289 autopsies over 25 years of age, 1919-1929. 25.7 per cent latent syphilitics.

In this material were two gummas of lung, one of pulmonary artery, two of spleen, two of bone, one of thyroid, two of skin.

\section{TABLE IV}

1909 to 1919. 386 Autorsies in Paiten'ts Over 25 Years of Age, With 169 Casts OF SYPHILIS SHOWING

\begin{tabular}{lr}
\hline Coronary sclerosis & 53 \\
Coronary syphilis & 9 \\
Coronary thrombosis and sclerosis & 1 \\
Angina pectoris & 0 \\
Sudden death & 13 \\
Sudden death with coronary selerosis & 9 \\
Sudden death with coronary syphilis & 4 \\
Sudden death with myocardial infarction & 4 \\
Sudden death with diffuse myocarditis & 9 \\
Myocardial infarction with coronary selerosis & 4 \\
Myocardial infaretion with coronary syphilis & 0 \\
\hline
\end{tabular}


In the decade 1919 to 1929. in the 332 cases of latent syphilis there were 172 cases of coronary sclerosis, and 55 cases showing syphilitic lesions of the coronaries, including one case of gummatous coronary arteritis. In this group there were five cases of coronary occlusion by thrombosis; four of these were associated with coronary sclerosis alone, and one with syphilis of the coronary. There were six cases of angina pectoris in this group; five of these were associated with coronary sclerosis alone, one with syphilis of the coronary main branches. There were twenty-five eases of sudden death in this decade in the syphilitic group; in thirteen of these the coronaries showed arterioselerosis alone; in twelve cases there were lesions of syphilis in the coronaries, six of these showed both syphilis and sclerosis. Eleven of the cases of sudden death showed myocardial infarction; fourteen showed no infarction, but the picture of a chronic diffuse interstitial myocarditis with fibrosis. Five of the cases of myocardial infaretion were associated with occlusion due to coronary sclerosis alone; six were associated with both sclerosis and lesions of syphilis.

TABLe $V$

19.9 to 1929. 1289 Autopsies IN PATIENTS Over 25 Years OF AgE, With 332 Cases of SyPhilis SHOWING

\begin{tabular}{lr}
\hline Coronary sclerosis & 172 \\
Coronary syphilis (1 gummatous arteritis) & 55 \\
Coronary thrombosis & 4 \\
Coronary thrombosis with coronary selerosis & 1 \\
Coronary thrombosis with coronary syphilis & 6 \\
Angina pectoris & 25 \\
Sudden death with coronary selerosis & 13 \\
Sudden death with \\
Sudden death with coronary syphilis & 12 \\
(With both sclerosis and syphilis, 6) & 11 \\
Sudden death with myocardial infarction & 14 \\
Myden death with diffuse myocarditis & 5 \\
Myocardial infarets with coronary sclerosis & 0 \\
Myocardial infarcts with sclerosis and syphilis & 6 \\
\hline
\end{tabular}

Coronary Syphilis.-Syphilis of the coronaries involves most frequently the smallest intermuscular branches; only rarely are the main divisions the seat of active syphilitic lesions. In the latter the process is usually of the nature of a periarteritis, the small vessels of the adventitia showing perivascular infiltrations and fibrosis, resulting eventually in obliteration. Sclerosis of the intima invariably results, and syphilis must be regarded as one of the causes of coronary selerosis, as it is of aortic. As aortic syphilis is always associated with coronary syphilis, the mouths of the coronaries may show the most marked sclerosis; in some cases they may be occluded by this process. In severe aortic syphilis this involvement of the coronaries may be limited to the first few millimeters, rarely more than 1 to 2 centimeters, of the main coronary. In our experience this occlusion of the coronary mouths 
associated with syphilis is due chiefly to the secondary sclerosis produced by the syphilitic process, and rarely by active syphilitic infiltration or proliferations, which are present about the vasa vasorum in the neighboring aortic wall, and about the small nutrient perivascular branches of the main coronary. In only one of our cases did thrombosis occur in the partially occluded mouth of the coronary. An active proliferating endarteritis due to, or associated with, active syphilis is relatively rare in the larger branches of the coronaries. Gummatous arteritis was found in one very active case of syphilitic aortitis and myocarditis. In one case only was the coronary thrombosis directly associated with an active syphilis of the coronary vessel; in four other cases the thrombosis was due to the secondary coronary sclerosis asso-

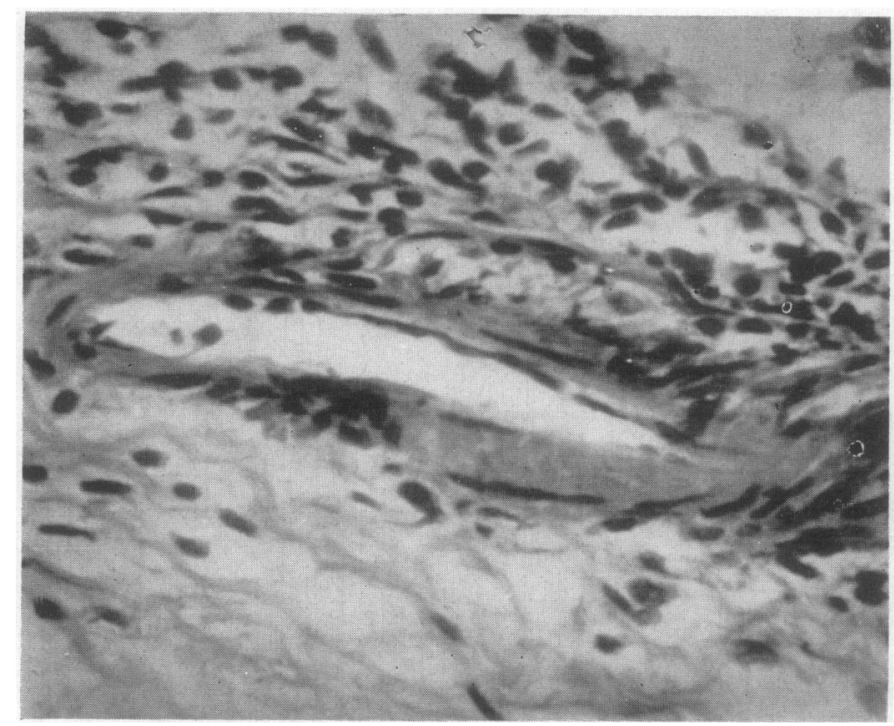

Fig. 1.-Active syphilitic perivascular infltration of small subepicardial coronary

ciated with the syphilitic process. In all of the cases of acquired syphilis with the exception of two, the syphilitic lesions were chiefly about the descending branch of the left coronary. Involvement of the right coronary and its branches is rare in acquired syphilis, although more common in cases of congenital origin. Myocardial infarction is but extremely rarely the result of a pure syphilitic involvement of the coronary vessels; in the great majority of cases the infarction is caused by occlusion by the atherosclerotic obliteration of the lumen, with or without thrombosis. Syphilis of the smaller branches of the coronaries leads to a slow atrophy and fibrosis of the myocardium, but rarely does it produce an anemic necrosis of the muscle. If cardiac infarction is the essential pathological condition underlying angina pectoris, as it would seem to be in our cases, this failure of syphilis to produce infare- 
tion of the muscle would account for the rarity of an angina pectoris history in our cases of active coronary syphilis without secondary sclerosis.

When we compare the nonsyphilitic cases coming to autopsy during the same two decades, we find that in 1174 nonsyphilitic autopsies there were 412 cases of coronary selerosis, with six cases of well-defined clinical angina pectoris, eight cases of coronary thrombosis and eight cases of myocardial infarction. In two cases sudden death from coronary thrombosis and myocardial infaretion occurred without a history of angina.

TABLE VI*

\begin{tabular}{|c|c|c|c|c|c|}
\hline PERIOD & $\begin{array}{c}\text { NO. } \\
\text { AUTOPSIES }\end{array}$ & $\begin{array}{l}\text { CORONARY } \\
\text { SCLEROSIS }\end{array}$ & ANGINA & $\begin{array}{l}\text { HYOCARDIAL } \\
\text { INFARCTION }\end{array}$ & $\begin{array}{l}\text { CORONART } \\
\text { THROMBOSIS }\end{array}$ \\
\hline $1909-1919$ & 217 & 52 & 1 & 1 & 1 \\
\hline $1919-1929$ & 957 & 360 & 5 & 7 & 7 \\
\hline
\end{tabular}

* Distribution of Coronary Sclerosis, Angina, Myocardial Infarction and Coronary Thrombosis in the Non-Syphilitic Autopsies in 20-year period, 1909-1929.

In Table VII the percentages of coronary sclerosis, angina, coronary thrombosis and myocardial infarction are compared for the two decades. For 1909 to 1919 the percentage of coronary sclerosis in the nonsyphilitic autopsies was 24 per cent, for the same decade it was $31+$ per cent in the syphilitic autopsies. For the decade 1919 to 1929 the percentage of coronary sclerosis in nonsyphilities was 38 per cent, in the syphilitic autopsies it was 52 per cent. The percentage of angina in the nonsyphilitic autopsies of 1909 to 1919 was 0.46 per cent, in the decade 1919 to 1929 it was 0.53 per cent. In the syphilitic cases there was no case of angina in 1909 to 1919 ; in 1919 to 1929 the percentage of angina cases was 1.8 per cent. In the decade 1909 to 1919 , in the nonsyphilitic autopsies the percentage of cases of myocardial infarction was 0.46 , for the decade 1919 to 1929 it was 0.74 . In the syphilitic autopsies the percentage of myocardial infarction was 2.4 for the decade 1909 to 1919 . and 3.3 for 1919 to 1929.

TABLE. VII

Percentages in Nonsyphilitics

\begin{tabular}{cccccc}
\hline \hline PERIOD & $\begin{array}{c}\text { NO. } \\
\text { AUTOPSIES }\end{array}$ & $\begin{array}{c}\text { CORONARY } \\
\text { SCLEROSIS }\end{array}$ & ANGINA & $\begin{array}{c}\text { MYOCARDIAL } \\
\text { INFARCTION }\end{array}$ & $\begin{array}{c}\text { CORONARY } \\
\text { THROMBOSIS }\end{array}$ \\
\hline $1909-1919$ & 217 & $24 \%$ & $0.46 \%$ & $0.46 \%$ & $0.46 \%$ \\
$1919-1929$ & 957 & $38 \%$ & $0.53 \%$ & $0.74 \%$ & $0.74 \%$ \\
& & PERCENTAGES & SN & SYPHILITICS \\
$1909-1919$ & 169 & $31+\%$ & 0 & $2.4 \%$ & $0.58 \%$ \\
$1919-1929$ & 332 & $52 \%$ & $1.8 \%$ & $3.3 \%$ & $1.5 \%$ \\
\hline
\end{tabular}

The most important thing revealed by the comparison of these charts is the fact that coronary selerosis, angina pectoris, coronary thrombosis and myocardial infarction have a higher rate of incidence in the syphilitic cases than in the nonsyphilitic. The significance of these 
facts must be that syphilis predisposes to the production of coronary atherosclerosis with its attendant pathology. While coronary occlusion, thrombosis, myocardial infaretion and angina pectoris are rarely the direct result of active syphilitic lesions of the coronaries, they all occur more frequently in the syphilitic, because of the more marked tendency possessed by the latter to develop severe grades of secondary atherosclerosis of aorta and coronary branches. Syphilis, therefore, secondarily and not primarily, is an important factor in the production of coronary disease and its concomitant angina pectoris.

Still more important is the relationship shown to exist between latent syphilis and sudden cardiac death, as given in Table VIII. Sudden death due to cardiac decompensation and dilatation was almost

\section{TABLE VIII}

Relation of Sudden Death to Coronary Sclerosis and Coronary Syphilis in 501 Cases OF SYPHILIS IN YEARS 1909-1929

\begin{tabular}{lr}
\hline Sudden death with coronary sclerosis & 22 cases \\
Sudden death with coronary syphilis & 16 eases \\
Sudden death with coronary sclerosis and syphilis & 6 eases \\
Sudden death with diffuse myocarditis & 23 cases \\
Sudden death with myocardial infarction & 15 cases \\
Sudden death with coronary thrombosis & 6 cases \\
Sudden death with coronary thrombosis and sclerosis & 5 cases \\
Sudden death with coronary thrombosis and syphilis & 1 case \\
\hline
\end{tabular}

five times as frequent in our latent syphilitics as in the nonsyphilitics. Many of these cases were coroner's autopsies. This bears out the writer's contention as to the importance of cardiac involvement as the frequent cause of death in the syphilitic. Syphilis acts both primarily and secondarily upon the heart. As a secondary factor it plays a large part in the production of aortic and coronary sclerosis; as a primary factor it produces myocardial insufficiency through the slow production of an interstitial fibrosis. Twenty-three of our cases of sudden death showed this lesion alone. In every one of these cases evidence of latent syphilis of the myocardium was found on serial sections, in the form of an increase of stroma cells and localized collections of lymphocytes and plasma cells. Valvular lesions were not present in any one of these cases. We therefore conclude that:

1. Active syphilitic lesions of the larger coronary branches are infrequent. They rarely produce occlusion of the vessel, or lead to thrombosis or myocardial infarction.

2. Arteriosclerosis of the coronaries, coronary occlusion, coronary thrombosis, myocardial infarction and angina pectoris are more frequent in the latent syphilitic than in the nonsyphilitic. Syphilis predisposes sccondarily to coronary and aortic sclerosis and their resultant cardiac pathology. 
3. Sudden cardiac death was almost five times as frequent in the syphilitic as in the nonsyphilitic autopsies. In the majority of cases this was due to cardiac insufficiency and dilatation, resulting from a diffuse interstitial myocarditis of slight degree, leading eventually to fibrosis.

\section{REFERENCES}

Levine, S. A.: Monograph. Coronary Thrombosis: Its Various Clinical Features, Baltimore, 1930, p. 12, Williams \& Wilkins Company.

Stone, W. J.: Angina Pectoris and Coronary Occlusion. With Notes on the Vascular Pathology in Coronary Disease, Warthin Ann. Vol., p. 143, 1927.

Willius, F. A., and Brown, G. E.: Am. J. M. Sc. 168: 165, 1924. 